\title{
Um olhar sobre as avaliações de Cursos de Graduação em Enfermagem
}

\author{
An overview of the evaluation of Nursing Graduation Courses \\ Una mirada sobre las evaluaciones de los Cursos de Graduación en Enfermería
}

\begin{abstract}
David Lopes Neto', Elizabeth Teixeira", Euclea Gomes Vale"I, Fátima Scarparo Cunha ${ }^{\mathrm{IV}}$, lara de Moraes Xavierv", Josicléia Dumêt Fernandes" ${ }^{\mathrm{VI}}$, Kaneji Shiratori ${ }^{\mathrm{VII}}$, Kenia Schmidt Reibnitz ${ }^{\mathrm{VIII}}$, Mara Regina Lemes de Sordi ${ }^{1 \mathrm{X}}$, Márcia Barbieri ${ }^{\mathrm{X}}$, Maria Inês Brandão Bocardi' ${ }^{\mathrm{XI}}$

'Universidade Federal do Amazonas. Manaus, AM. "Universidade do Estado do Pará. Belém, PA. I'IFaculdade Católica Rainha do Sertão. Quixadá, CE. ${ }^{N}$ Universidade Federal do Rio de Janeiro. Rio de Janeiro, RJ. ${ }^{V}$ Universidade de Brasília. Brasília, DF.

${ }^{V}$ Universidade Federal da Bahia. Salvador, BA. ${ }^{V I I}$ Universidade Federal do Estado do Rio de laneiro. Rio de Janeiro, RJ.

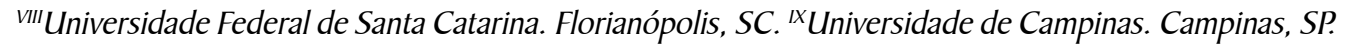
${ }^{x}$ Universidade Federal de São Paulo, SP. ${ }^{x I}$ Faculdades da Alta Paulista. Tupã, SP.
\end{abstract}

\begin{abstract}
Submissão: 20/11/2007
Aprovação: 20/12/2007

RESUMO

A investigação teve como objetivo, partindo do índice de aderência dos Projetos Pedagógicos dos Cursos de Graduação em Enfermagem às Diretrizes Curriculares Nacionais, analisar Qualitativamente potencialidades e fragilidades dos cursos. Estudo descritivo, comparativo, tendo como base os relatórios dos processos avaliativos conduzidos pelo INEP/MEC. Amostra constituída pelos relatórios para fins de reconhecimento e renovação de reconhecimento, realizados no período de 2002 a 2006, relativos a 12 cursos de graduação. Foram analisados 8 cursos localizados nos Quartis superior e 4 no inferior. O estudo revelou fortalezas e fraeuezas dos cursos nas três dimensões dos relatórios de avaliação, e aponta para a necessidade das escolas/cursos buscarem melhor vinculação entre a adoção das bases epistemológicas presentes nas DCN/ENF e as propostas nos PPC/ENF.

Descritores: Educação em enfermagem; Avaliação educacional; Programas de graduação em enfermagem.
\end{abstract}

ABSTRACT
This study aimed, starting from the index of adherence of the Pedagogical Projects of the Undergraduate Nursing Courses to the National Curriculum Rules for these Courses, to analyze Qualitatively potentialities and weak points of the courses. It is a descriptive, comparative study, between the present data in the PP/UNC and the proposed in the NCR/UNC, having as basis the reports of the evaluation processes conducted by the INEP/MEC. The sample was composed by the reports used for approval and reapproval, conducted in the period from 2002 through 2006, concerning 12 undergraduate courses. One analyzed 8 courses located in the superior part and 4 in the inferior. The study revealed strong and weak points of the courses in the three dimensions of the evaluation reports, and shows needs in the colleges/courses to search for a better use of the epistemologic bases present in the NCR/UNC and proposed in the PP/UNC.

Descriptores: Education, nursing; Educational measurement; Diploma nursing programs.

\section{RESUMEN}

Ésta investigación tuvo como objetivo, a partir del índice de adhesión de los Proyectos Pedagógicos de los Cursos de Graduación en Enfermería a las Directrices Curriculares Nacionales para esos cursos, analizar cualitativamente potencialidades y fragilidades de los cursos estudiados. Se trata de un estudio descriptivo, comparativo, entre los datos presentes en los PPC/ENF y los propuestos em las DCN/ENF, basado en los realatorios de los procesos evaluativos conduccidos por lo INEP/MEC. La amuestra fue compuesta por los relatorios con énfasis en el reconocimiento y renovación de reconocimiento, realizados en el período de 2002 a 2006 , relativos a 12 cursos de graduación. Fueron analizados 8 cursos localizados en los Quartis superior y 4 en el inferior. La investigación señaló puntos fuertes y además flacos de los cursos en las tres dimensiones de los relatorios de evaluación, y apunta la necesidad de las escuelas/ cursos en la busqueda de mejor vinculación entre la adopción de las bases epistemiológicas presentes en las DCN/ENF y las propuestas em los PPC/ENF.

Descriptores: Educación en enfermería; Evaluación educacional; Programas de graduación en enfermería.

Correspondência: INEP/MEC - Esplanada dos Ministérios, Bloco L - Anexos I e II, 4º andar. CEP - 70047-900. Brasília, DF. 


\section{INTRODUÇÃO}

Os dados oficiais do Ministério da Educação (MEC) revelam Que, a partir da década de 90 , a expansão da educação superior vem instigando as Instituições de Educação Superior (IES) a profissionalizarem as gestões administrativa e acadêmica, tendo como ferramentas o Plano de Desenvolvimento Institucional (PDI) e os Projetos Pedagógicos de Cursos (PPC). Este último com pertinência social e coerência com as Diretrizes Curriculares Nacionais (DCN) de cada curso de graduação que a IES oferece por meio de processo seletivo discente.

É neste contexto Que as DCN e o PPC assumem prioridade na agenda da educação superior. Porém, não basta definir DCN, é necessário implementá-las; não basta elaborar PPC, é necessário implementá-los com aderência às DCN; não basta expandir a educação superior, é necessário avaliá-la em busca da Qualidade e do compromisso com a justiça social e com as inovações cientificas e tecnológicas.

Por outro lado, estudos comprovam Que a apropriação das DCN pelos cursos de graduação da área da saúde vem evidenciando dificuldades na elaboração de novos PPC e posteriormente na sua implementação. A construção e re-construção de PPC, em grande parte das IES, estão restritas à adesão aos termos Que integram as DCN, sem contextualização das condições de saúde da população local/regional, da rede de serviços de saúde, da identidade do curso, assim como do perfil do egresso afinado às necessidades sociais e sanitárias, locais e regionais.

Em relação à configuração dos $\mathrm{PPC}$, outro aspecto Que merece destaQue é a nítida desarticulação entre os elementos descritivos e conceituais e a matriz curricular. As análises evidenciam que os elementos descritivos e conceituais são extraídos das DCN e incorporados, mecanicamente, ao PPC e a matriz curricular segue, ainda, o modelo de currículo mínimo, extinto pela LDB/I 996, com características de grade curricular, isto é, uma relação estática de disciplinas e cargas horárias sem coerência com a base epistemológica Que fundamenta esses elementos.

Pode-se constatar Que esta realidade da área da saúde, também, ocorre na Enfermagem, enQuanto campo de conhecimento Que tem como objeto principal o cuidado prestado ao ser humano, em todo ciclo vital, nos vários níveis de atenção em saúde.

Percebe-se, portanto, a necessidade de estudos que identifieuem as potencialidades e fragilidades dos cursos de graduação em enfermagem, no Que se refere à aderência às DCN/ ENF, com vistas ao oferecimento de subsídios para a formulação de políticas públicas de apoio a esses cursos.

Partindo desta percepção e da pesQuisa realizada pelo Ministério da Educação - MEC e pelo Ministério da Saúde - MS sobre a aderência dos cursos de graduação em saúde às $\mathrm{DCN}^{(1)}$, o presente artigo levanta o seguinte Questionamento: como se processa a implantação/implementação das DCN nos cursos de graduação em enfermagem, expressas nos PPC e em sua organização didáticopedagógica?

Buscando respostas a este Questionamento, o estudo tem como objetivo analisar a aderência das DCN/ENF registradas no contexto dos PPC de graduação em enfermagem, por meio dos relatórios de avaliação produzidos pelas Comissões designadas pelo INEP/MEC. Buscar a aderência entre as DCN/ENF e os PPC, significa ampliar a compreensão da realidade do processo de formação na enfermagem, nas suas diferentes concepções e práticas, haja vista a complexidade e o entendimento da incompletude dos saberes.

No alcance deste objetivo, pretende-se assim contribuir no planejamento e implementação de políticas de formação e inserção profissional no campo da saúde, na perspectiva do Sistema Único de Saúde (SUS), além de oferecer subsídios para as capacitações para o processo avaliativo dos cursos de graduação em enfermagem, em busca do desenvolvimento do compromisso formativo do avaliador, na elaboração dos relatórios e incorporação de aspectos Que revelem a mudança paradigmática na formação em saúde.

\section{AS DIRETRIZES CURRICULARES NACIONAIS COMO PRODUTO DO PARADIGMA EMERGENTE E O PROJETO PEDAGÓGICO DE CURSO COMO UMA DE SUAS EXPRESSÕES}

Em 1996, com a nova Lei de Diretrizes e Bases da Educação Nacional (LDB), Lei $n^{\circ} 9.394$ de $1996^{(2)}$, ficou explicitada a responsabilidade da União em assegurar o processo avaliativo, em nível nacional, objetivando a definição de prioridades e a melhoria da Qualidade do ensino. No Que se refere à área da saúde, esta Lei possibilitou a concretização, em 07/08/200 I, do Parecer 1.133 do $\mathrm{CNE} / \mathrm{CES}^{(3)}$, Que veio reforçar a necessidade da articulação entre Educação Superior e Saúde, objetivando a formação geral e específica dos egressos/profissionais, com ênfase na promoção, prevenção, recuperação e reabilitação da saúde. Após este Parecer, na área da enfermagem, foi aprovada a Resolução CNE/CES No 03 de $7 / 11 / 200^{(4)}$, Que definiu as Diretrizes Curriculares Nacionais para o Curso de Graduação em Enfermagem (DCN/ENF).

Em 2004, com a Lei $n^{\circ} 10.86^{(5)}$, foi criado o Sistema Nacional de Avaliação da Educação Superior - SINAES, Que foca a Qualidade da educação como propósito a ser buscado por meio da avaliação como instrumento de política educacional. Esta Lei imprime, ao sistema de avaliação, caráter formativo, interdisciplinar e intencional, além de articular a regulação da educação superior com a avaliação institucional, a de cursos de graduação e a de desempenho do estudante.

Além destas Leis, deve-se considerar o Decreto Federal no. 5.773, de 9 de maio de 2006, Que dispõe sobre o exercício das funções de regulação, supervisão e avaliação de instituições de educação superior e cursos superiores de graduação e seQüenciais no sistema federal de ensino. A partir deste marco legislativo, ficou evidente Que a expansão de cursos de graduação deve ocorrer, desde Que tenha Qualidade.

Neste sentido, a avaliação passou a ser peça fundamental na garantia da implementação das DCN/ENF como atividade orientadora para a elaboração de PPC inovadores, assegurando a aprendizagem centrada no aluno; a construção de currículo integrado, no Qual o eixo da formação passa a ser a prática/trabalho/cuidado de enfermagem; a articulação teoria/prática; as concepções de saúde enQuanto condições de vida; a presença de temas transversais; a concepção de avaliação como instrumento de (re)definição de paradigmas $^{(6-7)}$.

Coerente com o paradigma emergente, as DCN/ENF norteiam as IES na formação cidadã e profissional da(o) enfermeira(o), na definição dos componentes curriculares essenciais, na 
implementação de estágios curriculares supervisionados, na incorporação de atividades complementares e na organização do curso, tendo por base a flexibilização curricular. Além disso, destaca a importância da diversidade de cenários de aprendizagem, com ênfase no Sistema Único de Saúde (SUS) e na realidade locoregional, para proporcionar a integralidade das ações de enfermagem. Estes elementos necessitam estar relacionados ao processo de construção do conhecimento sobre o processo saúdedoença, nas diferentes fases do ciclo vital humano ${ }^{(4)}$.

Os PPC, tomando por base os padrões de Qualidade na formação do profissional cidadão no âmbito da graduação, pressupõem rupturas com o presente e promessas para o futuro, constituindose em ação intencional de pessoas, instituições e grupos, com sentido explícito, com compromisso definido coletivamente. Por isso, todo PPC é, também, projeto político por estar intimamente articulado ao compromisso sócio-político e com os interesses reais e coletivos da população majoritária, não podendo estar alijado do contexto social, uma vez Que ele é histórico e socialmente determinado.

Assim, com o novo paradigma Que se impõe, o PPC passa a consubstanciar a educação como fenômeno político e social Que se propõe a contribuir na formação de cidadãos conscientes de suas responsabilidades sociais e profissionais, engajados na luta por sociedade mais justa, digna, igualitária e solidária.

Avaliar a aderência dos PPC às DCN/ENF torna-se, destarte, processo necessário e de fundamental importância para a formação da (o) enfermeira(o), subsidiando o planejamento e a gestão das IES.

\section{METODOLOGIA}

O estudo utilizou a abordagem Quantitativa e Qualitativa ${ }^{a}$. Neste artigo apresentamos a análise Qualitativa, o Que permitiu interpretações dos dados, auxiliando na eliminação do arbitrário Que induz a modelos teóricos elaborados longe das situações empiricamente observáveis. Esta opção fundamentou-se no entendimento de Que todo conhecimento do cenário social, seja pelo olhar Quantitativo ou Qualitativo, só é possível por recorte, redução e aproximação e Que toda redução e aproximação não podem perder de vista o social ${ }^{(8)}$.

Para a coleta dos dados, foram considerados relatórios de reconhecimento e renovação de reconhecimento, disponibilizados pelo INEP/MEC, de 110 cursos de graduação. O trabalho foi desenvolvido em dois momentos e pautou-se em princípios do Grupo Focal e características da Validação de Especialistas.

No primeiro momento (Quantitativo), foram selecionados 60 aspectos $\left(\mathrm{I}_{60}\right)$ do instrumento de avaliação utilizado pelo INEP/ MEC, Que poderiam abordar temas apresentados nas DCN/ENF( ${ }^{(9)}$. A partir dos 60 aspectos, diretamente vinculados às DCN/ENF, foram selecionados I I $\left(\mathrm{I}_{1 \mathrm{I}}\right)$ aspectos, considerados mais relevantes ${ }^{(9)}$. Em seguida, chegou-se a um conjunto de 10 aspectos $\left(\mathrm{I}_{10}\right)$ Que foram considerados como aQueles Que abordam temas fortemente indicados nas DCN/ENF e Que foram considerados como capazes de expressar maior aderência às DCN/ENF ${ }^{(9)}$. Assim, o corpus de análise deste momento constituiu-se dos dados oriundos da aplicação do $\mathrm{I}_{60}$ e dos dados oriundos da aplicação do $\mathrm{I}_{10}$.

No segundo momento (Qualitativo), apresentado neste artigo, os critérios de inclusão dos relatórios dos cursos atenderam ao seguinte: cursos de bacharelado Que no banco de dados do INEP possuíssem o PPC e o respectivo relatório de avaliação elaborado por avaliadores/consultores do INEP; cursos localizados nos Quartis superior e inferior considerando a aplicação do índice de aderência $\mathrm{I}_{10}$. Atenderam a estes critérios 12 cursos de graduação em enfermagem assim distribuídos: 6 Faculdades e 2 Centros Universitários no Quartil superior; 3 Faculdades e I Universidade Pública no Quartil inferior.

A análise dos dados pautou-se na Análise de Conteúdo, aproximando-se da Análise Temática. Num primeiro momento, foi construída uma matriz (A) de análise, considerando aspectos capazes de expressar, via relatório, a relação entre o documento PPC e o movimento do curso na direção da concretização de sua proposta. Realizou-se a validação da referida matriz e posterior revisão de alguns aspectos com aperfeiçoamento subseQüente.

Após a organização e leitura dos dados obtidos com a aplicação da matriz A de análise (os membros do grupo de trabalho elaboraram análises por curso e uma síntese do resultado do conjunto de cursos), foram identificados 4 núcleos temáticos que emergiram do material produzido: 1) existência de referência textual no PPC às DCN/ENF; 2) existência de referência textual no PPC ao SUS; 3) presença, nos registros dos relatórios, de uma avaliação sobre a adesão dos cursos às DNC/ENF nas dimensões avaliativas elegidas; 4) abrangência do registro do avaliador sobre a realidade observada. Para orientar uma segunda leitura sobre o material (PPC e Relatório), foi construída uma nova matriz $\mathrm{B}$ de análise, com base nos núcleos temáticos supracitados e executada a aplicação.

A partir daí, procurou-se esclarecer as condições de produção do $I_{10}$, tentando focar com especial atenção o conjunto de cursos do Quartis superior e inferior. As perguntas a Que se buscaram respostas foram: O Que os cursos situados no Quartil superior possuem/ fazem que lhes potencializem a aderência às DCN/ENF? O Que os cursos situados no Quartil inferior carecem Que lhes comprometem a aderência às DCN/ENF?

Para obter respostas a estes Questionamentos, optou-se por realizar uma meta-avaliação das análises dos cursos situados nos dois Quartis supracitados, contrastando-os com os pressupostos presentes nos PPC e Relatórios. Os autores valeram-se dos dados obtidos por meio da aplicação dos dois instrumentos mencionados. Foram considerados, entre outros aspectos contidos nos instrumentos de avaliação, aQueles Que revelaram potencialidades e fragilidades dos respectivos cursos, no Que tange a aderência às DNC/ENF, bem como a menção de sugestões pelos respectivos avaliadores. O corpus de análise deste outro momento, constituiuse dos dados oriundos da aplicação das duas matrizes (A e B) aos 12 cursos localizados nos referidos Quartis, sendo Que 8 estavam classificados no Quartil superior e 4 no inferior.

Os dados registrados nos PPC e nos relatórios de avaliação dos referidos cursos, foram analisados, tentando-se captar aspectos concretos e diretamente influentes nos desafios da implantação das DCN/ENF. Os resultados a seguir cruzam as observações feitas com a aplicação das duas matrizes. Com este espírito, foram trazidos, ao texto, alguns cruzamentos realizados pelo grupo entre o PPC e o relatório, em Que também se evidenciou tanto a coerência entre ambos como a incoerência. Talvez possamos chamar a esse processo analítico de um esforço de meta-análise. 


\section{RESULTADOS}

Toda produção intelectual implica numa escolha, definida por uma intenção e situada em algum lugar, social e historicamente marcado. Ao se definir a realização deste mergulho Qualitativo, nos cursos cujo índice de aderência às DCN/ENF $\left(\mathrm{I}_{10}\right)$ localizava-se nos Quartis superior e inferior, foram assumidos alguns pressupostos, a saber: Afastamento de Qualeuer interesse do uso da lógica de classificação entre os cursos Que pudesse levar ao risco de comparação dos resultados de modo descontextualizado; Exame dos dados com garantia de Que os mesmos expressem o índice de aderência às DCN/ENF a partir da visão dos avaliadores, submetidos, portanto, a sua forma particular de interpretar e ajuizar o comportamento dos cursos em relação aos aspectos explorados no instrumento de avaliação.

\section{Cursos do Quartil Superior}

O resultado da aplicação da matriz B aos 8 cursos, evidencia Que 7 dos relatórios de avaliação foram considerados dentro dos núcleos temáticos "Atende às DCN/ENF sem reelaboração textual e/ou atribuição de sentidos" "e "Ausência de menção direta ao SUS".

A constatação da Qualidade de um curso neste estudo, revelada pela aderência às DCN/ENF, sofre a influência direta ou indireta de vários fatores, onde se destacam: a capacidade discursiva e prática de Quem organiza o material a ser avaliado; o olhar de Quem avalia; o Quanto os sujeitos estão implicados na luta pela Quebra paradigmática na saúde tendo apropriação (ou não) das concepções de saúde Que estão em jogo; a concepção de avaliação Que se possui; o formato avaliativo Que está sendo utilizado e a capacidade de aposta em uma outra cultura de avaliação.

Por este prisma, deve-se levar em conta a heterogeneidade do olhar do avaliador Quando registra suas impressões no relatório e a insipiência dos diferentes atores no trato dos significados éticoepistemológicos implícitos nas DCN/ENF, posto Que muitas avaliações fossem feitas muito próximas à aprovação das DCN/ ENF. Foi observado Que isto interferiu no processo de organização dos dados pelos cursos e com os juízos de valores dos avaliadores.

Nesta perspectiva, salienta-se a tendência dos cursos em reproduzirem ipisis literis o conteúdo do texto das DCN/ENF. Foi constatado Que vários dos textos produzidos pelos responsáveis pela gestão dos cursos limitaram-se a evidenciar seu compromisso com as DCN/ENF, pela incorporação Quase literal de seu conteúdo, sem Que se revele esforço de reelaboração, o Que poderia refletir esforço de construção do PPC com as marcas da IES. Evidentemente, isto ampliaria as chances de Que as decisões operacionais ligadas à concretização do PPC se efetivassem, revelando consistência da proposta escrita.

A referência ao SUS foi valorizada para tentar captar a adesão ao modelo de formação em saúde SUS-centrado, ou seja: comprometido com as necessidades dos usuários, pautado na integralidade e intersetorialidade, haja vista Que os profissionais de saúde são formados para potencializar mudanças nos cenários da prática e nos espaços Que podem fazer diferença no padrão de assistência Que é prestada à população e Que se expressam neste momento histórico de implantação do SUS. Evidentemente, a menção ao SUS e ao perfil epidemiológico da região em Que se insere o curso, sinaliza a compreensão de Que o PPC deva levar isto em conta na sua fase de operacionalização, se concretizando nas escolhas evidenciadas na forma de organização didático-pedagógica, principalmente na seleção dos cenários de aprendizagem e nas formas de relacionamento com os serviços entre outras.

Acredita-se Que, no processo de avaliação dos cursos, os avaliadores não podem se contentar apenas com indicativos discursivos de aderência às DCN/ENF, mas buscar evidências mais palpáveis de que a inovação possa estar acontecendo ou em vias de ser viabilizada, ainda que a médio e/ou longo prazo.

O resultado da aplicação da matriz A, a Dimensão Organização Didático-pedagógica foi considerado central para sustentar a implantação das DCN/ENF e, assim, a aderência deve ser retratada indubitavelmente. Foram indicados, a partir dos PPC e relatórios analisados, as potencialidades e fragilidades desta dimensão:

Potencialidades: Coordenação do curso articulada ao corpo docente; Existência de apoio pedagógico regular aos docentes com agenda programada; Correspondência da proposta pedagógica ao Que se visualiza na prática; Diferentes níveis de complexidade dos objetivos no PPC, favorecendo o alcance do perfil estabelecido; Integração do curso com outras áreas do conhecimento, com desenvolvimento de trabalhos conjuntos; Participação efetiva de alunos em projetos de extensão; AdeQuação da carga horária entre teoria e pratica.

Fragilidades: Adequação do projeto didático do curso, necessitando pequenos ajustes na distribuição da carga horária das disciplinas referentes à atenção básica, para Que haja maior ênfase nessa área, e uma organização mais eqüitativa para os três níveis de assistência, com atualização na nomenclatura de algumas disciplinas; Ausência de integração entre as disciplinas; necessidade de atualização das ementas; Inexistência das características inovadoras propostas pelas DCN/ENF; PPC não expressa articulação com SUS, está aQuém da dinâmica de funcionamento do curso; Pesquisa docente incipiente; Sistema de acompanhamento de egressos em fase de elaboração; Os objetivos do curso e perfil do egresso, apesar de definidos, apresentam pouca coerência com as atividades acadêmicas propostas.

Quanto a aplicação da matriz B, é importante destacar Que foi identificado, em 7 cursos, o núcleo temático "Avaliação da aderência presente e sustentada no texto do avaliador" e, em apenas I curso, esteve presente o núcleo "Aderência fraca ou inexistente".

Isto leva a se interrogar sobre o Que está em jogo, Quando se avalia algo, com ou sem apresentação de evidências Que sustentem e objetivem os juízos de valor sobre a Qualidade Que se está interessado em desvelar. Como negar Que se pode mudar a sorte de um curso ou de uma proposta de formação ao se descuidar da descrição pormenorizada daQuilo Que se prioriza ao olhar?

Disto resulta a importância da avaliação in loco e a capacitação do avaliador para desenvolver acurácia e comprometimento com as mudanças paradigmáticas, tanto na saúde como na educação. A sua clareza conceitual sobre as mudanças a Que a avaliação deve referenciar, podem resultar conseqüências Que postergam ou aceleram as rupturas necessárias. A partir daí surgiram duas constatações: a avaliação pode tornar visíveis contradições, limites, dilemas e auxiliar o avaliador a construir possibilidades de superação junto ao grupo avaliado, fazendo valer a formatividade da avaliação; 
ou pode o avaliador, com seus juízos de valor, tornar menor ou inexistente as fragilidades da proposta de inovação, fazendo desaparecer, como por encanto, a insuficiência da inovação, exceto pela incorporação dos jargões da mudança.

O avaliador necessita ter atenção tanto ao Que está dito como ao Que está subliminar nos cursos, razão pela Qual seu relatório é peça fundamental de informação ao sistema e ao curso, desde que acrescente evidências Que sustentem seus juízos de valor, tornando possível o diálogo e a crítica em busca da superação.

Essas considerações estão ilustradas nos fragmentos dos registros da meta-análise, apresentados a seguir:

"O relatório dá sustentação aos indicadores selecionados, porem, após leitura do PPC, evidencia-se Que não há integração entre as disciplinas na matriz curricular e, ao mesmo tempo, ao apresentar a orientação pedagógica Que se diz integrada, descreve o desenvolvimento de 3 eixos temáticos compostos por disciplinas isoladas" (UTkI).

"Outra incoerência é no processo avaliativo que tem um discurso inovador com aplicação de conceitos suficiente (S), parcialmente suficiente (PS) e insuficiente (I), Que depois são transformados em notas por tabela de equivalência” (UTkI).

"O perfil do egresso sustenta-se em competências gerais e especificas afinadas às DCN, porém, não há identidade do curso tampouco aderência à realidade local/regional" (UTf 4).

"Observa-se uma intencionalidade do PPC em desenvolver ações de implantação das DCN sem, contudo, estar explicitada a concretude da aderência do PPC aos princípios das DCN/ENF; 0 relatório de avaliação não registra esta atividade" (UTe3).

"Vale destacar Que o relatório de avaliação não registra uma lacuna importante, pois se mantém o sistema de grade curricular' com disciplinas estanQues e sem articulação" (UTjl).

"Ficou evidente a integração das atividades de ensino com os cenários da prática desenvolvidos no sistema local de saúde" (UTkI).

"Existe coerência do sistema de avaliação com a concepção do curso e são adequados os procedimentos de avaliação do processo" (UTk3).

"Os avaliadores revelam que o observado in loco difere do PPC. No momento da avaliação foi apresentado um novo PPC Que atende as DCN/ENF havendo clareza e detalhamento das informações" (UTj2).

Um dos maiores problemas em processos de inovação curricular, como se pode perceber, é a construção da coerência entre o professado e a realidade onde residem os grandes limites à operacionalização dos novos referenciais teóricos e onde devem se concretizar as rupturas nas opções epistemológicas Que, anteriormente, faziam sentido. Tal transição gera grande desconforto aos atores envolvidos, sejam docentes, estudantes e profissionais inseridos nos cenários da prática.

Sendo assim, uma nova forma de organização do trabalho pedagógico implica, também, na criação de espaços de reflexão coletiva sobre o projeto, a serem concretizados na incerteza dos novos caminhos. A figura mediadora do coordenador potencializa a tarefa do grupo e catalisa suas energias na direção de um outro paradigma, no caso em Questão, as DCN/ENF e seu compromisso com a consolidação do SUS.

Na aplicação da matriz B aos 8 cursos, foi constatado que os registros se aproximavam do núcleo temático “Apreensão dinâmica da realidade do curso", evitando o "Registro estático do estabelecido". Isto indicou que se pode depositar confiança nos dados analisados e prosseguir neste esforço de meta análise. Admite-se que o grande desafio para o êxito das DCN/ENF reside na indução dos cursos em buscar aderência aos seus pressupostos, o Que reclama por ação dos sujeitos Que darão visibilidade a estes compromissos.

Assim, olhar a Dimensão Corpo Social é condição sine qua non para manter a saúde do PPC, tomada neste estudo como a aderência às DCN/ENF. Nos registros dos documentos foram identificadas as seguintes potencialidades e fragilidades desta dimensão:

Potencialidades: Corpo docente com boa experiência profissional fora do magistério superior, sendo a maioria mestre e doutor; Registro de política de capacitação; Há plano de carreira que contempla a disponibilidade de carga horária docente para o desenvolvimento de atividades complementares, propostas pelas DCN/ENF; A maioria dos professores tem formação adequada às disciplinas que ministram, da mesma forma, a maioria possui experiência pedagógica; Parte possui boa experiência na docência e uma outra é composta por iniciantes nesta atividade; Há referências de incentivos e ações sistematizadas para o desenvolvimento das atividades de pesQuisa e extensão e horas de capacitação e orientação para os alunos.

Fragilidades: Carências nas ações de capacitação que ocorrem eventualmente; A atenção aos projetos de extensão é pouco significativa; Há necessidade de incremento nos projetos de pesQuisa para incentivo e engajamento dos alunos na iniciação cientifica; No Que se refere ao plano de carreira, pode-se considerar Que há necessidade de melhoria nas ações de capacitação, devendo as mesmas ocorrer de forma mais sustentada e não eventualmente.

Nessa dimensão, foi identificado um conjunto de sugestões dos avaliadores, no sentido de superação da realidade encontrada:

Definição de critérios de admissão e de progressão dos docentes; Adequação do PPC às DCN/ENF, particularmente no Que se refere à flexibilidade curricular, integração das disciplinas, atividades complementares, articulação com os cenários das práticas, perfil do egresso, metodologias ativas e processos avaliativos; Carga horária semanal do professor em atividades complementares, em orientação didática extra-classe, redimensionamento das atividades acadêmicas; Deixar claro no PPC Quais os campos das práticas Que são utilizados pelas atividades acadêmicas, assim como a existência de ações sistemáticas de articulação dessas atividades com a rede de serviços de saúde local/regional.

Essas considerações estão ilustradas com os registros da metaanálise, a seguir: Não fica visível a proporção de regime de trabalho docente (UTkI); Não se especificam Quais são as atividades complementares Que já estão em curso (UTk3); Manifesta a preocupação com a capacitação pedagógica, e relata varias atividades desenvolvidas em anos anteriores (UTe2); Há registros de uma política de capacitação docente e de integração docente-assistencial com planejamento de atividades conjuntas (UTe5).

Finalmente, na Dimensão Infra-estrutura, buscou-se captar como os cursos se comportavam na seleção dos cenários de aprendizagem para identificar se levavam em conta os compromissos com a diversidade e as necessidades do modelo assistencial. No geral, no Que se refere às instalações e laboratórios 
específicos, foram observadas condições favoráveis ao desenvolvimento das atividades acadêmicas Que podem favorecer a coerência com as DCN/ENF e estão registradas no relatório de avaliação, como se pode observar nos registros da meta-análise:

Vale salientar Que nem no PPC, nem no Relatório de Avaliação, constam Quais os campos das práticas Que são utilizados pelas atividades acadêmicas, nem tampouco a existência de ações sistemáticas de articulação dessas atividades com a rede de serviços de saúde local/regional (UTj3); $\boldsymbol{O}$ relatório não sustenta as afirmações referentes aos cenários de aprendizagem, e o PPC também é sucinto na apresentação destes cenários sem articular justificativa plausível com a realidade loco regional (UTk3); $\boldsymbol{O}$ relatório não sustenta as informações referentes aos cenários, contudo, o PPC justifica a escolha de acordo com a realidade regional (UTk I); Registram-se cenários da prática Que dão sustentação ao processo ensino aprendizagem e boa integração docente assistencial com possibilidade de desenvolvimento profissional (UTe2).

\section{Cursos do Quartil Inferior}

Importa para esta análise reforçar Que, no presente estudo, não há interesse em Questionar a veracidade deste indicador, mas aproveitar a sinalização Que ele possibilita, para tentar entender o contexto Que afeta os cursos de enfermagem / instituições e que pode estar definindo esse índice tão baixo e preocupante para o modelo assistencial do país.

Se no Quartil superior foi observada uma forte aderência dos cursos ao discurso das DCN/ENF, mesmo com algumas limitações, neste Quartil foi observado o desconhecimento do Que representam as DCN/ENF.

Foram identificados 4 cursos Que se situaram neste Quartil e Que, portanto, revelaram baixa aderência aos aspectos que constituem o $\mathrm{I}_{10}$. Estão abaixo de 25\% de aderência. Dentre eles, estão 3 faculdades privadas e I universidade pública. Tendo em vista Que, neste indicador, os cursos têm naturezas administrativas diferentes (público e privado), foi feita análise em separado.

No curso da universidade pública aparece como registro o núcleo temático "Não atende às DCN/ENF", destacando-se que o relatório do avaliador sustenta a afirmação de não aderência, embora se aproxime do núcleo "Registro estático do estabelecido", como se houvesse uma "mera leitura da palavra escrita sem agregar a esta uma leitura de mundo". Curioso é que o registro tem como período da avaliação, o segundo semestre de 2004, o Que leva à indagação de Quais as razões da demora em proceder aos ajustes, e mais do Que isso, Quais as implicações de não se ter ainda atualizada a formação dos enfermeiros para fazer frente aos desafios de uma sociedade submetida a processos de mudança acelerada?

Há registro que "Há fraqueza em todos os quesitos". Surgem fragilidades na Dimensão Organização Didáticopedagógica, pois "Não se assegura formação generalista; não se evidencia efetivo desenvolvimento de projetos de investigação científica que possibilitem expandir a participação dos alunos; há problemas no apoio didático-pedagógico que é considerado insatisfatório". Foi destacado como potencialidade "A experiência profissional e acadêmica da coordenadora Que participa de varias comissões na IES e em colegiados de diferentes níveis decisórios".

Na Dimensão Corpo Social, as fragilidades foram: "Despreparo didático-pedagógico; rotatividade pelo contrato temporário; limitação na participação na elaboração $e$ desenvolvimento do PPC". A Dimensão Infra-estrutura igualmente destacou a "Necessidade de investimentos para aQuisição de equipamentos imprescindíveis ao ensino da avaliação física e práticas técnicas". Surgiu como potencialidade a riQueza dos cenários da pratica Que apresentam ótimas oportunidades de ensino-aprendizagem

$\mathrm{Na}$ análise global assinala-se como surpreendente no relatório de avaliação, o conceito emitido Que não se revela coerente com o Quadro descrito pelo avaliador e em especial considerando esta uma universidade pública.

Nas três faculdades privadas, duas tiveram PPC atendendo às DCN/ENF, com reelaboração textual e na outra foi observado o atendimento sem reelaboração textual e acréscimo de sentidos do grupo local. Não há Qualeuer menção sobre o SUS em dois destes cursos. Os relatórios de avaliação destes cursos foram considerados como de boa Qualidade, na medida em Que evidenciam uma apreensão dinâmica da realidade com texto do avaliador, sustentando o juízo de valor sobre a aderência.

Dimensão Organização Didático-pedagógica

Potencialidades: Existência de apoio pedagógico; Implantação de plano de carreira.

Fragilidades: Estágios curriculares Que não atendem às DCN/ ENF;PPC Que não se alinha às DCN/ENF;Dimensionamento inadequado das cargas horárias das disciplinas; Copia literal das DCN/ENF.

\section{Dimensão Corpo Social}

Fragilidades: Os estágios são supervisionados por enfermeiros preceptores com contrato temporário e Que não participam dos conteúdos teóricos; Para a supervisão dos conteúdos práticos a relação numérica professor/aluno não é suficiente, pois algumas atividades são realizadas na capital conforme relato dos alunos presente no relatório; $O$ regime de trabalho do docente é compatível com as disciplinas Que ministram, mas não possibilitam atividades de pesquisa;Pouco tempo de experiência profissional e docente.

\section{Dimensão Infra-estrutura}

Fragilidades: No acervo de livros, nos laboratórios, na implementação das normas de biosegurança entre outros; $\mathrm{Na}$ existência de cenários de praticas abrangentes como o indicado nas DCN;

\section{ALGUMAS LIÇÕES DO PROCESSO}

Apreender a substantividade do objeto apreendido é uma das habilidades do sujeito do processo, Que se denomina, neste estudo, avaliador-educador. $\mathrm{O}$ ato de relatar essa apreensão da realidade pode ser mecânico, em Que se transfere/confere/constata (mas não é esse o relato Que ser Quer). O relato também pode ser dinâmico, em Que se constrói/reconstrói/constata para mudar (e é esse Que se Quer); esse é o papel do avaliador-educador.

A tarefa da avaliação dos cursos não é simples e deve ser objeto de capacitação permanente. No caso dos cursos da saúde, isto implica em atenção, também, aos significados Que estes atores (avaliadores e avaliados) atribuem às novas e contra-hegemônicas concepções Que se tenta viabilizar. Não se deve desconhecer que o esforço de apropriação dos pressupostos é processual, não linear e submetido a constantes embates, frutos das concepções de 
Qualidade da formação em saúde em disputa. Cabe, também, ao avaliador, reconhecer e valorizar os esforços do grupo Que tenta inovar e Que encontra limite nas condições objetivas de trabalho oferecidas institucionalmente ou nas formas de organização dos sistemas de saúde da região em Que se insere o curso.

O olhar dos avaliadores para os PPC marca, de alguma maneira, as formas de produção do relatório, ampliando seu viés regulatório ou emancipatório. Ou ainda, talvez, permitindo exercitar uma "regulação orientada para emancipação". Ou seja, à tarefa de regulação deve se associar o sentido pedagógico-politico da avaliação, estimulando a comunidade do curso a compreender as contradições do processo de implantação de um processo de formação inovador.

Por Que não pensar Que o papel do avaliador-educador é contribuir positivamente para Que o curso vá sendo "o artífice de sua formação" com a ajuda necessária do avaliador-educador? Por Que não imaginar Que sua presença pode ser auxiliadora desse processo e "possa significar como estímulo [...] à ruptura necessária com algo defeituosamente assentado e à espera de superação"?

Acredita-se Que a posição do avaliador-educador, primeiramente, tem de ser de respeito (às pessoas Que Queiram mudar e às Que se recusem a isso). No entanto, não se pode negar ou esconder as posturas e nem desconhecer os direitos dos outros de rejeitá-las. E é exatamente em nome do respeito aos outros Que não se deve omitir e nem tão pouco assumir uma neutralidade Que não existe. A omissão do avaliador-educador em nome do respeito ao corpo social do curso "[...] talvez seja a melhor maneira de desrespeitá-los"(10).

Nessa perspectiva, a avaliação realizada nos cursos de graduação em enfermagem pode ser considerada como um processo interativo através de leitura documental, interação local, ações, observações, onde os avaliadores aprendem sobre a realidade no próprio ato da avaliação. Deve-se considerar, ainda, Que na maioria das vezes o PPC não traz subsídios suficientes Que respaldem a avaliação in loco, fato Que interfere e prejudica o relato do avaliador, levando em consideração o tempo restrito na Qual acontece a avaliação de curso.

A leitura e análise dos PPC e dos Relatórios dos avaliadoreseducadores, apontaram resultados indicando Que um dos saberes necessários à prática educativa é a "apreensão da realidade". Dessa apreensão destacam-se:

- A formação de profissionais Enfermeiros deve estar voltada para a integralidade dos problemas de saúde da população brasileira, necessitando ser contextualizada e resolutiva, fundamentando-se em PPC que possibilitem práticas de saúde com responsabilidade social.

- Os Cursos de Graduação em Enfermagem, como agentes influenciadores na formação de seus estudantes, Que no futuro irão interferir na Qualidade e organização dos serviços de saúde, devem ter o compromisso de formar profissionais Que atendam às exigências do Sistema único de Saúde, consolidando os seus princípios de universalidade, integralidade, hierarQuização e descentralização.
- O Projeto Pedagógico de Curso deve ser o instrumento teórico-metodológico responsável em direcionar pensamentos e ações à formação acadêmica dinâmica, contextualizada na realidade local, regional e nacional, enraizada em princípios éticos universais e peculiares ao exercício profissional.

- O processo da interdisciplinaridade deve acontecer por meio de planejamento conjunto e participativo, valorizando as competências, os valores, as atitudes, o saber-fazer, o saber-estar, desenvolvendo capacidade de criatividade, comunicação, trabalho em equipe, resolução de problemas, responsabilidade, poder empreendedor, Que são ferramentas importantes na adaptação à geografia mutacional e organizacional do mundo do trabalho.

- A interdisciplinaridade deve exigir, de todos os atores envolvidos no processo de formação, o desenvolvimento de uma ação pedagógica articulada com a diversidade dos saberes. A ação de cada um deverá estar articulada com a de todos os outros. Todos os envolvidos no processo pedagógico deverão ser capazes de perceber sua totalidade.

- A aderência do PPC às DCN/ENF precisa se concretizar na perspectiva da busca do domínio filosófico e pedagógico dos princípios, diretrizes, estratégias e ações consagradas pela Resolução CES/CNE 03/2001.

- O PPC deve garantir a identidade institucional, das diversidades do sistema de ensino federal e regional/cultural e da responsabilidade social, sem perder a aderência à Qualidade da formação acadêmica do futuro enfermeiro, respeitando os princípios norteadores das DCN/ENF.

- A implantação e implementação dos PPC aderentes às DCN/ ENF devem se constituir num processo de construção coletiva, produzindo ruptura paradigmática com modelos antagônicos ao pautado pelas DCN/ENF.

A apreensão dessa realidade indica alguns desafios, como por exemplo, a necessidade de capacitação dos avaliadores, reforçando a discussão teórico-filosófica sobre a mudança de paradigma no processo pedagógico e na concepção de saúde, articulados aos princípios estabelecidos no Sistema Único de Saúde, resgatando a formação de profissionais Enfermeiros, voltada para a integralidade dos problemas de saúde da população brasileira, mais especificamente, loco-regional, para Que a assistência à saúde oferecida seja contextualizada e resolutiva.

Outro ponto a ser considerado como desafio na formação de avaliadores-educadores é a necessidade de construir, coletivamente, protocolos de avaliação Que tratem da temática complexa "expansão com Qualidade com respeito às diversidades regional e cultural e à identidade institucional”, garantindo às especificidades da área da saúde e da enfermagem.

Finalmente, é importante explicitar Que os resultados deste estudo representam recortes da problemática enfocada, sem a pretensão de tratá-la na sua totalidade. Assim, percebe-se a necessidade de estudos, outros, Que realizem uma análise mais ampla dos Projetos Pedagógicos Institucionais (PPI) e dos Planos de Desenvolvimento Institucionais (PDI).

\section{REFERÊNCIAS}

1. Ministério da Saúde (BR). Ministério da Educação. A aderência dos cursos de graduação em enfermagem, medicina e odontologia às diretrizes curriculares nacionais / Ministério da Saúde, Ministério da Educação. Brasília (DF): Ministério da 
Saúde; 2006.

2. Brasil. Lei no 9.394, de 20 de dezembro de 1996. Dispõe sobre as bases e diretrizes da educação nacional. Brasília (DF); 1996.

3. Ministério da Educação e Cultura (BR). Conselho Nacional de Educação Câmara da Educação Superior. Parecer $n^{\circ}$ 1. 133, de 07 de agosto de 200 I. Dispõe sobre as Diretrizes Curriculares da Medicina, Enfermagem e Nutrição. Brasília (DF): Ministério da Educação e Cultura; 2001.

4. Ministério da Educação e Cultura (BR). Conselho Nacional de Educação, Câmara da Educação Superior. Parecer no 3 , de 7 de novembro de 200 I - institui as Diretrizes Curriculares Nacionais do Curso de Graduação em Enfermagem. Brasília (DF): Ministério da Educação e Cultura; 2001.

5. Brasil. Lei n ${ }^{\circ}$ 10.86 I de 14 de abril de 2004. Institui o Sistema Nacional de Avaliação da Educação Superior - SINAES. Brasília (DF); 2004.
6. Fernandes ID, Ferreira SLA, Oliva DSR, Santos MP, Costa HOG. Estratégias para a implantação de uma nova proposta pedagógica na Escola de Enfermagem da Universidade Federal da Bahia. Rev Bras Enferm 2003; 56(4): 392-5.

7. Fernandes ID, Xavier IM, Ceribelli MIPF, Bianco MHC, Maeda D, Rodrigues MVC. Diretrizes Curriculares e estratégias de implantação de uma nova proposta pedagógica. Rev Esc Enferm USP 2005; 30(4); 443-9.

8. Minayo MCS. O desafio do conhecimento: pesquisa Qualitativa em saúde. São Paulo (SP): Hucitec-Abrasco; 2004.

9. Lopes Neto D, Teixeira E, Vale EC, Cunha FS, Xavier IM, Fernandes ID, et al. Aderência dos cursos de graduação em enfermagem às Diretrizes Curriculares Nacionais. Rev Bras Enferm 2007;60(6): 627-34.

10. Freire P. Pedagogia da autonomia. $17^{\mathrm{a}}$ ed. São Paulo (SP): Cortez; 2003. 